\title{
A CASE OF AORTIC ANEURYSM
}

INVOLVEMENT OF SENSORY NERVE-ROOTS; SPONTANEOUS FRACTURE OF VERTEBRAL COLUMN;

LAMINECTOMY ; DEATH

BY

HORACE TURNEY, M.D.OxoN., F.R.C.P.

ASSISTANT PHYSICIAN TO ST. THOMAS'S HOSPITAL

$\triangle N D$

CHARLES A. BALLANCE, M.S.Lond., F.R.C.S. ASSISTANT SURGEON TO ST. THOMAS'S HOSPITAL

Keceived September 14th, 1898-Read January 10th, 1899

WilliaM B-, aged 35, seaman. Admitted to St. Thomas's Hospital September 14th, 1897 ; died October 24th, 1897.

Family history.-Father is alive and healthy; the mother died of bronchitis. Nothing points to inherited disease.

Previous history. - Patient had a hard chancre seventeen years ago, which was followed by a rash, but no other secondary symptoms. He was treated with black wash, but took no medicine. Four years later he married; his wife is quite healthy, and has borne him three healthy children, but has had one miscarriage. None of the children have apparently shown any sign of inherited syphilis. Until the commencement of the present illness patient had always enjoyed good health, and had been quite free from accidents.

Present illness.-This began two years ago, when 
patient first noticed pain in the middle of his back, which came on without any apparent cause. He attended the Seamen's Hospital, Poplar, for it, and was given a liniment. The pain at first was not constant, but recurred some three or four times a week, generally at night. It was of an aching character, and soon extended round his body at the same level. These attacks have become more and more frequent, and for the last four months have been practically continuous. Of late, however, the pain in the back has become quite subordinate to that referred to the lower and anterior part of the thorax. Movement seems to have no effect upon it, though the back has felt stiff ever since the first onset. Four months ago patient spent three weeks in Sydney Hospital; but deriving no benefit from the treatment, he returned to England. In Sydney and on board ship he had injections of morphia about once a week, and occasional sleeping draughts. During the last four months he has lost at least two stones in weight.

State on admission.-Patient is a powerfully built man, but thin, and with a well-marked expression of pain on his face. He complains in a wailing voice of intense pain in the upper abdomen and back. He keeps on repeating expressions such as "I can't bear it any longer," and seems constantly on the verge of tears.

Nervous system.-No loss of power or affection of sensation can be detected in the extremities, either upper or lower, and no trophic changes are evident in either skin or muscles. The knee-jerks are present and equal on the two sides, and no cloni can be elicited. - The superficial reflexes are equally unaltered. The sphincters act normally, and have always done so. The mental condition is clear, but shows distinct loss of emotional control, which, under the circumstances, is not surprising. In fact, so far as the nervous system is concerned, all signs of disease are limited to a zone of the trunk. The patient refers the pain mainly to the following area, which is of roughly triangular shape, and situated on the anterior right 
side of the chest (see Plate I, Fig. 1). Its upper border is horizontal, and touches the lowest point of the fifth rib; the lower margin starts from the middle line about an inch below the tip of the ensiform, and after pursuing at first a horizontal course, runs upwards and outwards to meet the upper boundary in the anterior axillary region. The inner vertical margin corresponds to the middle line of the trunk, and unites the inner ends of the lines just described. The skin over this area is intensely hyperæsthetic, the patient flinching and often crying out with pain when it is gently pinched between the finger and thumb. The borders are well defined, the hyperæsthesia suddenly disappearing at the periphery. Tactile sense, on the other hand, is slightly impaired. For example, two points which are recognised as distinct elsewhere are merged into one over the hyperæsthetic area, though on account of the excessive sensitiveness it is difficult to make an altogether satisfactory examination. There is no change in either the vascular or trophic condition of the skin.

The corresponding triangle on the left side of the body is not hyperæsthetic, and at present pain is not referred to that spot, though apparently it has been in the past. The only change which can be detected in its sensory functions consists in some blunting of tactile sense, such as has been already described on the opposite side. In the back there is no zone of hyperæsthesia, and no deep tenderness except on pressure over the tenth dorsal spine.

Spinal column.-The rigidity of the back at once attracts attention; this is not limited to any one part, but is more marked in the upper dorsal and cervical regions. The stiffness applies both to antero-posterior and to lateral movements. The patient can move about in bed, and even walk about the ward, without any increase in the pain, and absolutely no effect is produced by firm pressure applied to the head or shoulders. The back shows a very distinct deformity; the upper half of the dorsal spine has 
the normal backward curve visibly exaggerated. This curve terminates rather abruptly, the spinous process which forms the extreme end of the prominence being the eighth dorsal, while the site of maximal projection is occupied by the seventh dorsal. Below the eighth spine there is a marked concavity, the floor of which is formed by the ninth and tenth dorsal spines. The tenth spine is extremely tender. A sponge wrung out of hot water does not produce the least pain at any spot in the column. 'There does not appear to be any lateral irregularity.

The abdomen is normal in every respect.

Chest.-The cardiac dulness begins above at the fourth left costal cartilage ; the apex-beat is in the fifth interspace, half an inch internal to the left nipple line, while the limit of dulness to the right corresponds with the left margin of the sternum. The sounds are normal both at base and apex, while the rhythm is regular at 72 per minute.

The urine has a specific gravity of 1030 , is loaded with urates, and contains neither albumen nor sugar.

On September 21st the tenderness noticed over the tenth vertebral spine was found to have altogether disappeared. Since admission patient had had one or two injections of morphia, and a mixture of cannabis indica with tincture of gelsemium, but without much effect on the pain.

The hyperæsthetic area was less distinct than on admission.

On September 25th the patient, who was very anxious to get up, was allowed to do so. This did not appear to have any effect on the pain one way or the other; but on September 30th the pain grew worse, and he went back to bed, where he thereafter remained. On October 1st specific treatment was commenced in the form of inunctions of mercury and potassium iodide internally, increased rapidly to 30 grains three times a day. On October 11th (see Plate I, Fig. 2) the pain was referred to the left, side of the chest more than to the right, and in conjunction with 


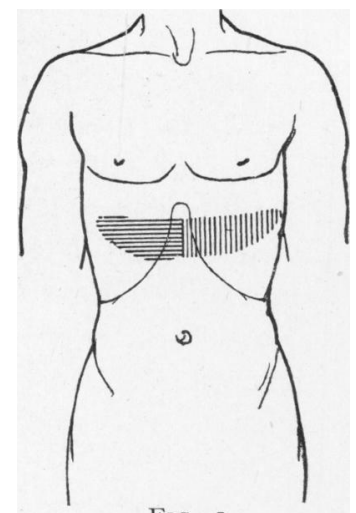

FIG. I.

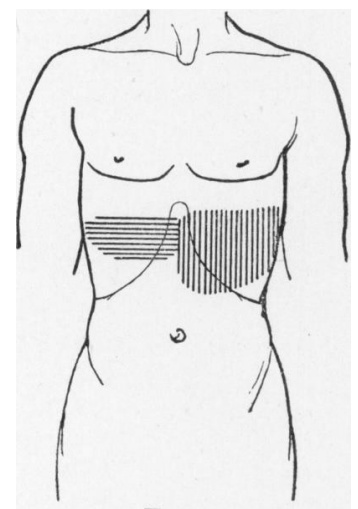

FIG. 3.

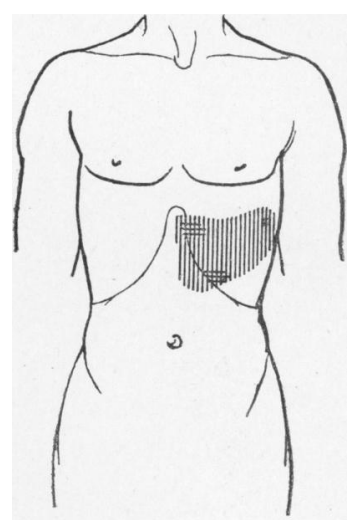

FIG. 2.

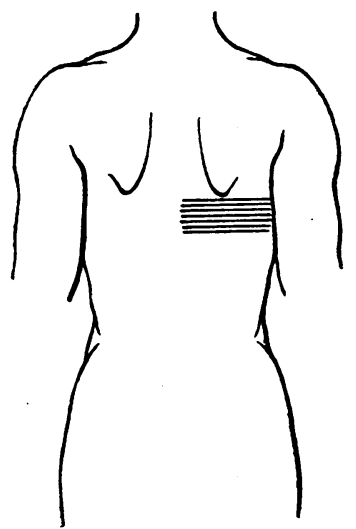

Fis. 4.

I)r. Túrney and Mr. Ballaxce's Paper.

Fig. I. - Area of altered sensation as found on the patient's admission on Sept. 14.

Fig. 2. - Condition on Oct. I I.

Fig. 3.-Condition on Oct. 18 ; anterior view.

Fig. 4. - Posterior view ; condition on Oct. 18.

The horizontal shading indicates hyperæsthesia.

The vertical represents partial anæsthesia. 
this, hyperæsthesia of an extreme degree had developed over a triangular area corresponding to that originally noted on the right, but extending below the costal margin for about two inches. On the same day patient complained of difficulty in swallowing, referring the stoppage to the mid-sternal region. $\mathrm{He}$ stated that he had to drink some water after taking solid food before he could get it down. On October 12th the pain was referred alternately to the one side and the other. October 18th. -Plate I, Figs. 3 and 4 show the condition observed on that day. On October 21 st patient complained that everything that he ate or drank burned him inside.

On October 23rd patient was being washed in bed, when he called out and instantaneously lost power in his legs. He described his sensations as being like a lightning shock all through him; the pain seems to have been intense. Immediately afterwards his left leg and thigh were completely paralysed; the right lower limb retained a trace of power, for he was able to move his toes and his knee slightly. When seen some hours later his condition was as follows:

He was quite unable to raise himself or even to turn over in bed. The abdominal muscles were acting, but the lower intercostals were completely paralysed ; at all events, there was no movement of ribs from the sixth downwards, except that imparted by the diaphragm. The abdominal reflexes were brisk, the epigastric absent. Retention of urine existed for the first time; the bowels had not acted since the attack. In the lower limbs the condition was very much that described immediately after the onset of the paralysis, but some improvement had taken place. In the left, motor power was all but completely absent; the only sign of it lay in slight movements of the toes. On the right side a certain degree of power remained in all parts of the limb, but the movements were excessively feeble. As regards sensation, little if any alteration could be detected above the knee; below that level there was very considerable blunting of sensation of every kind without 
complete abolition anywhere. This blunting was more marked on the left side than on the right. The condition of sensation over the zone of hyperæsthesia, to which frequent reference has been made, is depicted in the diagram, Plate I, fig. 3. Plantar reflexes could not be obtained on either side, but the knee-jerks were brisk. There was no clonus and no rigidity.

It was at once decided that laminectomy should be performed, but in view of the improvement that had taken place in the patient's condition during the day, and the great disadvantage of operating by artificial light, it was deemed wise to wait till the following morning.

Immediately before the operation on October 24th the condition remained unaltered.

October 24th (Operation):-The patient being placed in a convenient position and anæsthetised, the usual steps in the performance of a laminectomy operation were carried out (see Plate II). The laminæ of the sixth, seventh, eighth, and ninth dorsal vertebræ were removed. After a little dissection of fat and areolar tissue the theca was exposed, and it at once became evident that the upper part of the spinal column was free of and completely separated from the lower between the sixth and eighth vertebræ. The finger was passed by the side of the theca into the space which should have been occupied by the body of the seventh dorsal vertebra, but which now was filled by a mass of recent red currant jelly clot. This clot reached the spinal theca in front, and was supposed to have been due to sudden hæmorrhage from or into a sarcomatous tumour. The finger was passed more than once into the clot mass as far as possible, and no idea presented itself to the mind at the time that a search was being instituted into the interior of an aortic aneurysm. No hæmorrhage occurred. The wound was closed, and dressings applied in the ordinary manner. While the operation was proceeding it was noticed that after the removal of the laminæ the lower ribs, which had previously been paralysed, had resumed their function. 


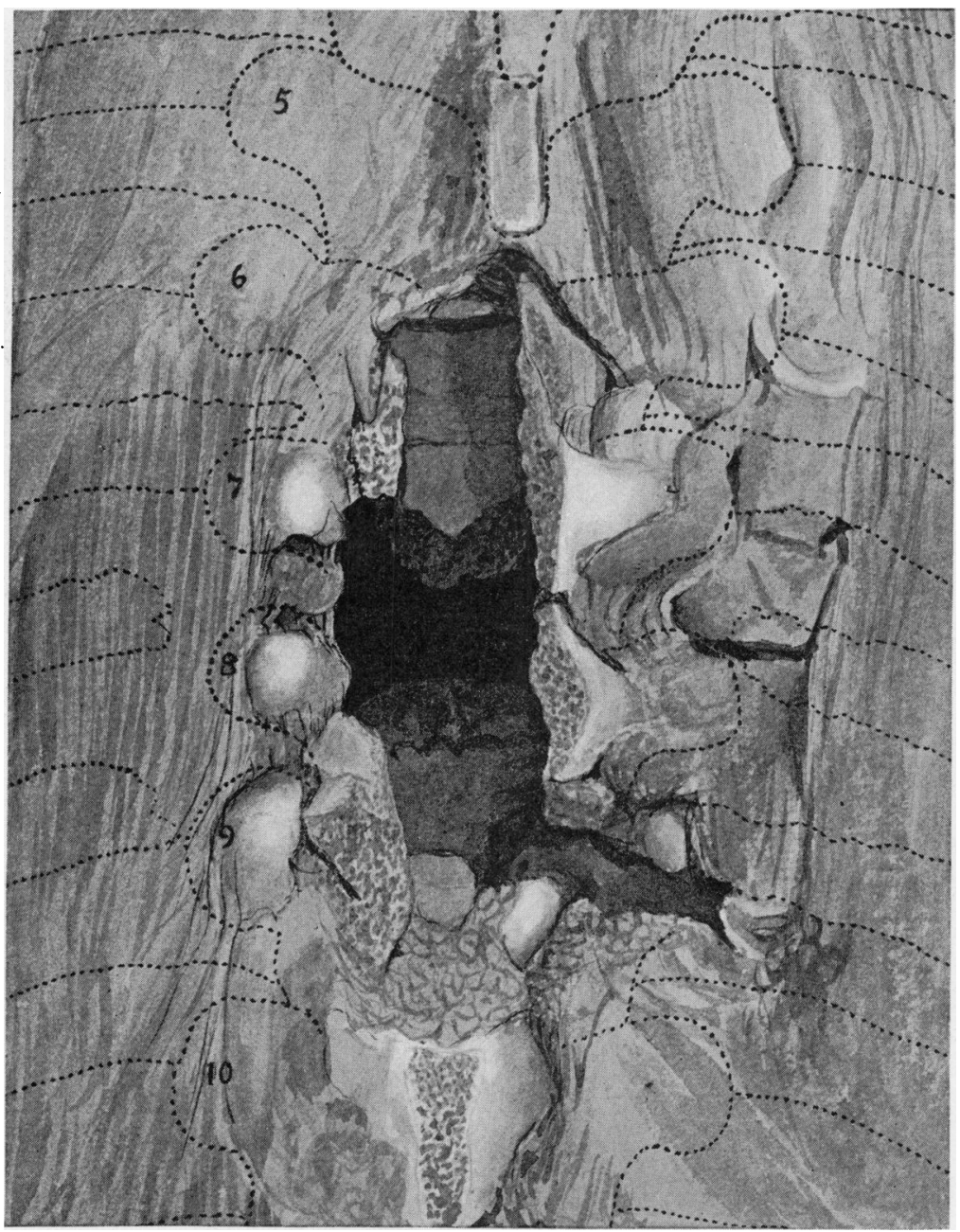

Dr. Tukney and Mr. Ballance's Paper.

( $\frac{4}{5}$ nat. size.) The region of the operation is exposed. The spinal theca was removed before the drawing was made. The opening of the Aneurism into the Spinal Canal by the pressure destruction of the body of a vertebra is clearly seen. 
After the operation the patient was taken back to the ward in a state of great collapse, from which he never really recovered. Hypodermic injections of strychnine were given, and as much in the way of stimulants by the mouth as was possible, but in spite of this life was prolonged for eight or ten hours only, and death occurred without any return to full consciousness. Unfortunately the patient's condition precluded any attempt at further examination.

Post-mortem examination.-The body is that of a poorly nourished man; rigor mortis present.

Thorax.-The thorax being opened, the heart appears lying in the normal position, and overlapped by the lungs as usual. The organ is of normal size and proportions, and appears to be altogether free from disease. The same may be said of the lungs and pleuræ.

On the inferior concavity of the transverse arch of the aorta is a small aueurysm. It is of the size of a small sweet chestnut, which may be imagined to be stuck on to the artery by its flat surface. The small bag thus formed is completely filled by.dense white laminated clot; the aneurysm is, in fact, in the condition commonly mistaken for one of cure. From the posterior aspect of the extreme lowest part of the descending arch another aneurysm has sprung, but of a very different type. This forms a tumour measuring vertically four and a half inches and transversely five inches. At the spot from which the aneurysm arises the aorta shows remarkably little sign of disease; there is a hole cut in the posterior wall of the vessel, about an inch and a half in vertical measurement and three quarters of an inch in transverse. Against this externally the aneurysmal sac is, as it were, opposed. The sac is full of clot (see Plates III and IV), which is mainly of the currant jelly type, though this is mixed with a good deal of tough decolourised material. The wall of the sac has no definite layer of laminated fibrin in contact with it. In position the tumour is exactly symmetrical, reaching about an inch and a half on either side of the vertebral 
bodies. Its upper border is very slightly above the aperture of communication with the vessel, and corresponds to the fifth dorsul vertebra, while the lower is as low as the tenth. Over its anterior surface runs the œsophagus, much stretched and flattened out.

Spinal column (anterior view).-The body of the sixth dorsal vertebra is eroded, that of the seventh is practically destroyed, and in places the finger comes down on the posterior ligament; even the intervertebral disc has disappeared. At this spot there is a complete solution of continuity in the spinal column. The destruction of the eighth dorsal vertebra is considerable but not complete, while the ninth is eroded like the sixth.

The ribs are affected on the left side from the sixth to the eleventh, while on the right side the change extends only from the sixth to the tenth. The heads of the seventh and eighth ribs and their bodies for an inch or more outside this are destroyed, while in the others the destructive process has not advanced beyond a more or less considerable erosion (see Plate III).

Spinal column (posterior view).-The laminæ have been removed from the sixth to the ninth dorsal inclusive. At the level of the seventh the finger can be passed through the anterior wall of the spinal canal straight into the cavity of the aneurysm; still there appears not to have been any considerable escape of clot or blood into the canal. At this level the upper part of the column moves freely on the lower in an antero-posterior direction, though the internal ligaments are not altogether destroyed. The upper portion of the spine is dislocated backwards, so that there is a sharp angle at this point.

The spinal membranes are healthy.

Spinal cord.-This does not appear flattened out, but at the spot (the level of the seventh dorsal) where it has to follow the sharp bend of the bony canal there is a section about half an inch in length, the tissue of which feels distinctly soft. [The cord was placed in Müller's fluid for further examination.] 


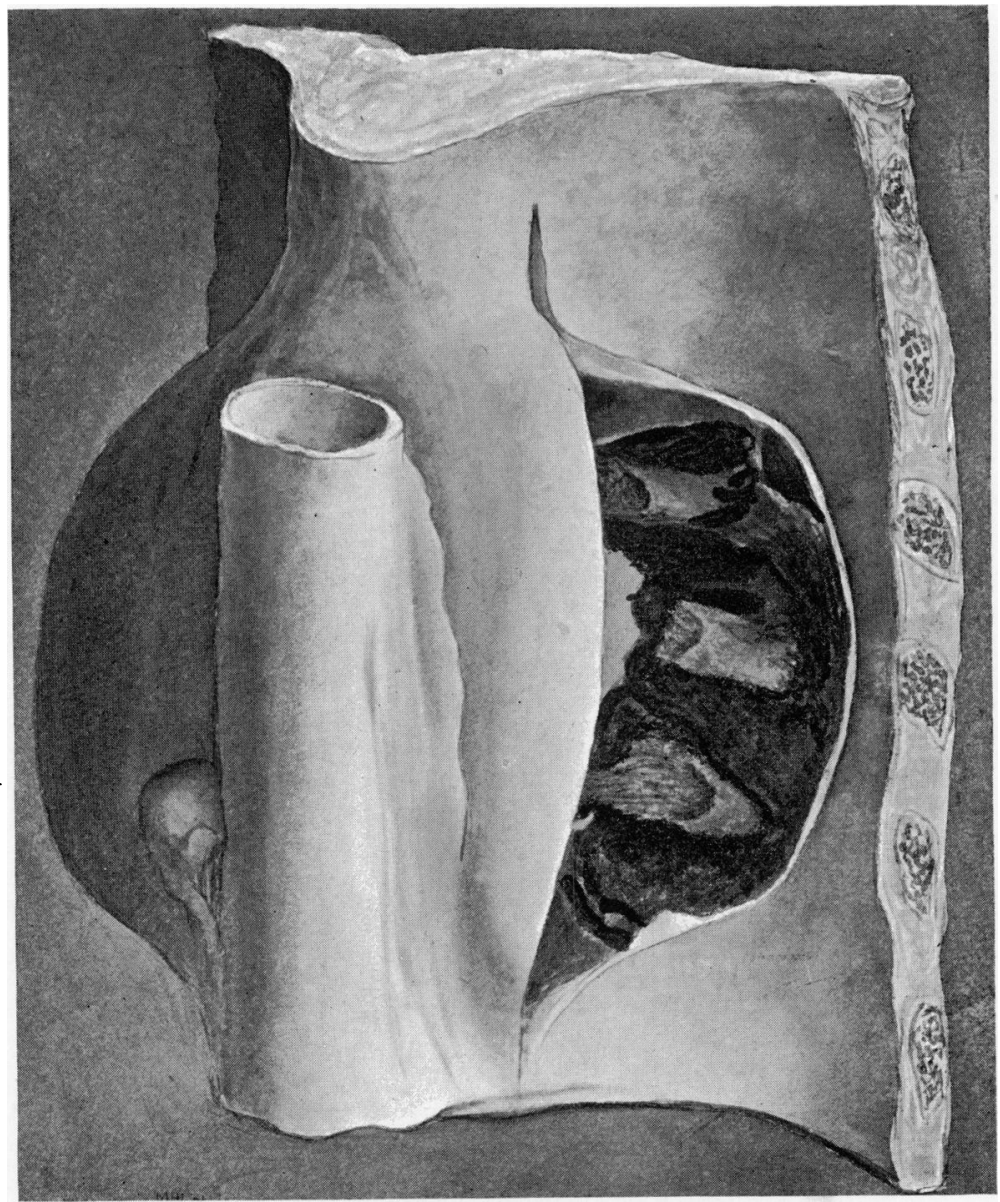

Ir. Turney and Mr. Ballance's Paper.

( $\frac{4}{5}$ nat. size.) View of Aneurism and descending Aorta from the front. Through the window made in the wall of the Aneurism the Erosion of the ribs is seen. 


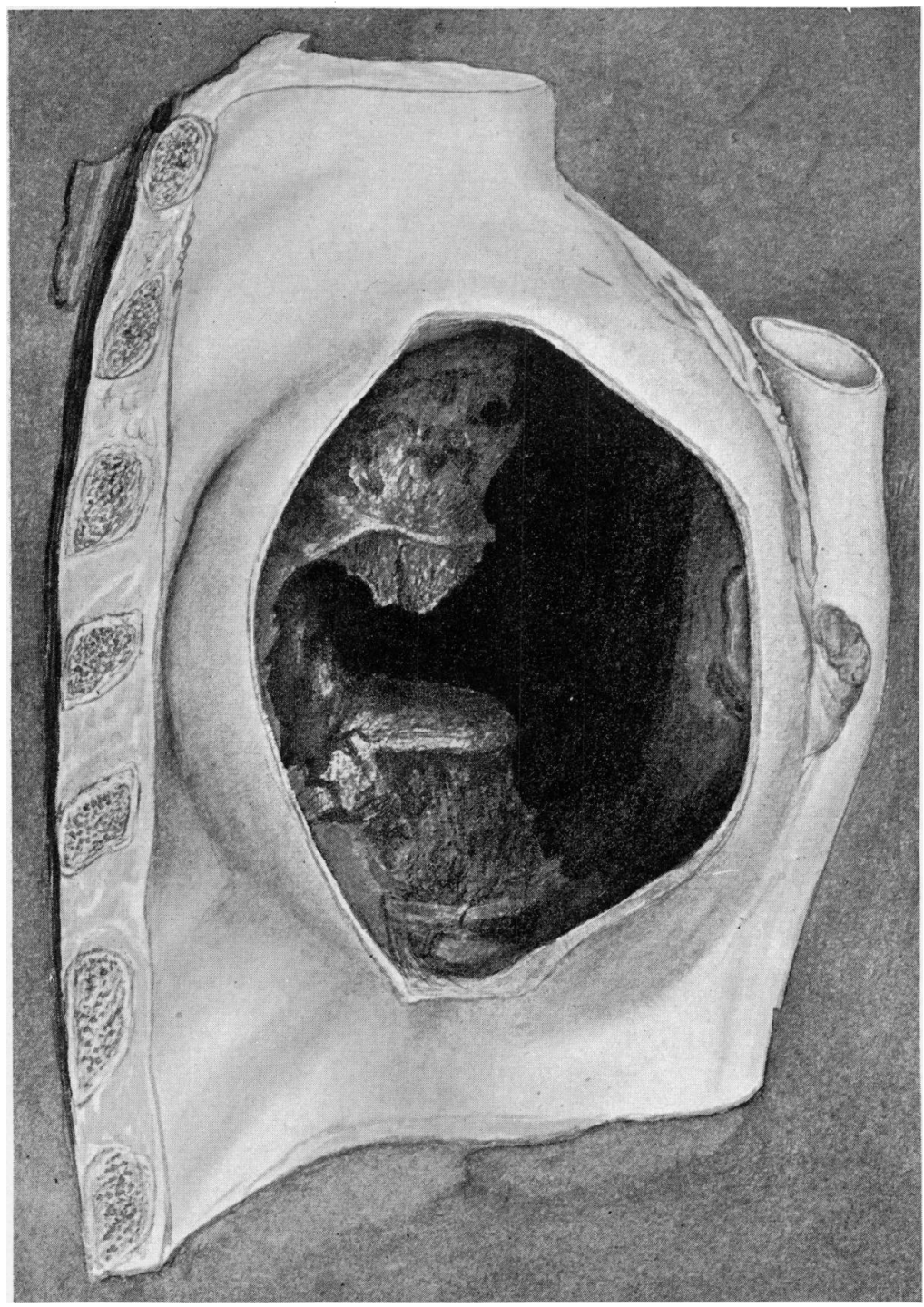

Dr. Turney and Mr. Ballance's Paper.

( $\frac{4}{5}$ nat. size.) A portion of the wall of the Aneurism has been removed on the right side. The disappearance of the body of one vertebra and the erosion of others are shown. 
Nerve-roots. - The only two to show any change visible to the naked eye are the seventh roots on either side. The left posterior root in particular is swollen and bright pink in colour. Its fellow on the opposite side is similarly altered but to a less extent, while the anterior root on that side (the right) shows as great change as the posterior root on the left. No change can be detected in the eighth roots on either side. The abdominal viscera are normal.

Microscopical examination (by Dr. Pdrves Stewart).Sections of the seventh left posterior dorsal root showed its blood-vessels to be markedly engorged, as compared with those of the normal fifth posterior root. There was no obvious connective-tissue proliferation between its nerve-fibres.

No degeneration was found in any of the nerve-roots nor in sections of the spinal cord, as high as the fifth and as low as the eighth dorsal segments, either by the method of Marchi or by that of Weigert-Pal.

Remarks.-It will have been gathered from the foregoing account that the case was one which throughout presented remarkable difficulties in the way of a correct diagnosis. The physical signs pointed strongly to some gross disease of the spinal column either primary or secondary. The symptoms, however, had remained absolutely stationary ever since their first appearance no less than two years before, and were limited in the most striking manner to those associated with irritation of posterior nerve-roots. No final conclusion was reached, but the diagnosis appeared to lie between pachymeningitis on the one hand and aneurysm, growth, and tubercular caries on the other. But whichever was accepted considerable difficulties had to be met. As against pachymeningitis the unusual and strict localisation of the lesion, and the failure of the hypothesis to explain the condition of the spine, had to be taken into account, while in favour of it was the history of previous syphilis. It 
was finally put out of court by the negative results of a thorough course of specific treatment.

The possibility of caries was thoroughly discussed and rejected. Clinically the case did not correspond in the least with any example of that disease which either of us had seen or heard of. The completely negative result of the hot sponge test, which is by some regarded as all but pathognomonic, counted against it, while the persistence of symptoms of irritation without any signs either of advance or retrogression for so prolonged a period seemed practically conclusive.

A most careful examination failed to reveal any evidence, direct or indirect, of the existence of an aneurysm; the heart was normal in every respect, the sounds were not conveyed with any unusual force to the back, and the symptoms had from the first been symmetrical. Moreover the condition of the spinal column was hardly that which one would regard as compatible with aneurysm. Taking everything into consideration, the chances seemed to be in favour of growth. The length of the history and the unchanging character of the symptoms offered difficulties which were great indeed, but still less insurmountable than those which appeared to confront every other diagnosis. The great loss of flesh which had undoubtedly occurred was strongly confirmatory, and the transient difficulty in swallowing was at least as compatible with growth as with aneurysm. When the final attack of paraplegia occurred doubts became almost certainties, and even on the operation table nothing was found which appeared inconsistent with the theory of growth.

Little remains to be said on the neurological aspect of the case; our knowledge of the distribution of sensory areas has been made so complete by the researches of Sherrington and Head that no difficulty arose in deciding which nerves were involved. It is satisfactory to note that the localisation was confirmed by the autopsy. From the first it was plain that the seventh dorsal posterior root, 
and later also the eighth, were the sufferers, and so it proved.

The sudden attack of paraplegia was in all probability the result of pressure by the dislocated vertebræ; the slight movement in bed was sufficient to rupture the last remaining bony link between the upper and lower sections of the spinal column. At the same time it is possible that the sudden access of symptoms was due to a rapid extension of the aneurysm.

It is noteworthy that at the time of the operation the finger passed within the sac without traversing anything of the nature of a limiting membrane, the clot alone preventing the outrush of blood. The destruction of the intervertebral discs by the pressure of an aneurysm is so rare an occurrence as to merit special notice. In caries, as is well known, the discs between the affected vertebræ disappear at an early stage of the disease; in aneurysm, on the other hand, the bones suffer, while the discs remain intact.

(For report of the discussion on this paper, see 'Proceedings of the Royal Medical and Chirurgical Society,' Third Series, vol. xi, p. 43.) 